\title{
A (IN) CONSTITUCIONALIDADE DA PENHORA DO IMÓVEL RESIDENCIAL (BEM DE FAMÍLIA LEGAL) DO FIADOR NO CONTRATO DE LOCAÇÃO A PARTIR DA DOUTRINA PERANTE A APLICAÇÃO DOS PRINCÍPIOS E DIREITOS FUNDAMENTAIS
}

\author{
(UN) CONSTITUTIONALITY OF THE \\ SEIZURE OF RESIDENTIAL PROPERTY \\ (LEGAL HOMESTEAD) THE GUARANTOR \\ ON LOCATION CONTRACT FROM THE \\ DOCTRINE WITH APPLICATION OF \\ FUNDAMENTAL PRINCIPLES AND RIGHTS
}

\section{Jaciara dos Santos Motta ${ }^{1}$}

RESUMO: O presente artigo tem por objetivo analisar a (in)constitucionalidade da penhora do imóvel residencial (bem de família legal) do fiador no contrato de locação a partir dos posicionamentos doutrinários perante a aplicação dos princípios de direitos fundamentais. Abordou-se, primeiramente, o bem de família no que diz respeito a sua origem e aos tipos deste existente na legislação pátria e, em seguida, a penhora do imóvel residencial (bem de família legal) do fiador no contrato de locação diante do posicionamento do Supremo Tribunal Federal
(STF), o qual atualmente, bem como os Tribunais de Justiça segue o entendimento consolidado de que é penhorável o bem de família legal do fiador no contrato de locação. Por último, se analisa os posicionamentos doutrinários perante a aplicação dos princípios de direitos fundamentais acerca da constitucionalidade e da inconstitucionalidade da referida penhora.

Apesar de já possuir entendimento consolidado, inclusive com repercussão geral, o breve estudo em apreço busca analisar a constitucionalidade

1 Advogada, graduada em direito pela Universidade do Sul de Santa Catarina (UNISUL), Campus Tubarão - SC, especialista em Direito Constitucional Aplicado (Faculdade Educacional Professor Damásio de Jesus).Email: jaciaradossantosmotta@gmail.com. 
ou não da referida penhora de acordo com a doutrina perante a aplicação dos princípios de direitos fundamentais.

Palavras-chave: Bem de Família Legal. Fiador. Locação.

ABSTRACT: The objective of this article is to analyze the (un) constitutionality of the seizure of the residential property (legal homestead) of the guarantor on location contract from the doctrinal positioning before the application of fundamental principles and rights. Legal homestead was first discussed with regard to its origin and the types of homestead existing in the national legislation and then the of the seizure of residential property (legal homestead) the guarantor on location contract in what matters to the position ofthe Federal Superior Court
(FSC), which currently, as well as the Courts of Justice, follows the consolidated understanding that the legal seizure of the residential property (legal homestead) of the guarantor on location contract. Finally, the doctrinal positions before the application of the fundamental principles and rights regarding the constitutionality and unconstitutionality of said seizure.

Although it already has a consolidated understanding, including with general repercussion, the brief study, seeks to analyze the constitutionality or not of the said seizure according to the doctrine before the application of fundamental principles and rights.

Keywords: Legal homestead. Guarantor. Location.

\section{INTRODUÇÃO}

O tema abordado no presente trabalho trata da temática referente à penhora do imóvel residencial (bem de família legal) do fiador no contrato de locação, ou seja, sobre a (in) constitucionalidade pelo olhar doutrinário perante a aplicação dos princípios de direitos fundamentais. $\mathrm{O}$ tema em questão está amparado no artigo $3^{\circ}$, inciso VII da Lei 8.009/90, acrescido pelo art. 82 da Lei 8.245/91, que permite a realização da penhora do imóvel residencial do fiador decorrente de contrato de locação.

No ano de 2005, o Supremo Tribunal Federal, decidiu pela inconstitucionalidade desta penhora, porém, em 2006, nova decisão correspondeu a sua constitucionalidade. Em agosto de 2010, por meio de Repercussão Geral se consolidou o entendimento do Supremo Tribunal Federal (STF), da constitucionalidade da penhora do imóvel residencial do fiador no contrato de locação, e no ano de 2015 o Superior Tribunal de Justiça (STJ), 
emitiu súmula a respeito desta penhora pela sua validade. Assim, tal entendimento permanece atualmente, nos Tribunais Superiores e nos Estaduais.

Contudo, é possível averiguar na doutrina posicionamentos divergentes acerca deste tema perante os princípios de direitos fundamentais aplicados ao presente caso.

Mediante o fundamento desta divergência doutrinária perante os princípios e direitos fundamentais, é que o presente estudo irá ater-se para verificar se existe ou não inconstitucionalidade acerca desse tipo de penhora.

\section{ORIGEM DO BEM DE FAMÍLIA}

O bem de família tem a sua origem no direito norte-americano (EUA), conhecido como homestead, regulamentado pela lei de 26 de janeiro de 1839 (homestead exemption act), do Texas, no início do século XIX, anterior à própria incorporação aos EUA (1845). (AZEVEDO, 2002, p. 19).

Segundo Azevedo (2002, p. 25):

Homestead significa local do lar $($ home $=$ lar; stead $=$ local), surgindo em defesa da pequena propriedade. Mostra-nos Pierre Jolliot que a origem e a razão de ser do instituto do homestead se encontra no espírito do povo americano, dentre outras causas, pelo respeito da atividade e da independência individual, pelo sentimento herdado da nação inglesa, de considerar a casa como um verdadeiro castelo sagrado e pela necessidade de estimular, por todos os meios, os esforços do colono ou do imigrante, no sentido de uma maior segurança e proteção em caso de infelicidade.

Após os Estados Unidos da América (EUA) se libertarem da força repressiva da Inglaterra, o território norte americano foi sendo ocupado e, devido ao solo fértil, a agricultura e ao comércio, se desenvolveram de maneira célere através do trabalho árduo do povo. Assim, os bancos europeus fixaram-se nesta pro- 
missora região, possibilitando operações bancárias, reunindo os pequenos capitais americanos e prestando serviços à economia norte americana, impulsionando cada vez mais a agricultura, o comércio e a indústria local. (AZEVEDO, 2002, p. 24).

Em face dos grandes benefícios realizados pelos empréstimos, tais como: escolas, hospitais, canais, estradas, fábricas etc., se criou a ilusão dourada do lucro fácil, a qual levou o povo a ultrapassar os limites da realidade no que tange aos demasiados empréstimos e ao elevadíssimo nível de vida. Mediante estes fatos, instalou-se nos EUA a grande crise econômica entre os anos de 1837 a 1839. (AZEVEDO, 2002, p. 26).

Com a ocorrência deste fato, os credores começaram a realizar penhoras em massa nos bens dos devedores, mesmo sabendo que naquele momento, qualquer possibilidade de se obter o crédito era nula. Assim, os devedores sofriam execução da penhora em seu patrimônio que era composto de terra, animais e instrumentos agrícolas por preços irrelevantes tendo em vista o valor pago antes da crise. Em paralelo com a crise que assolava os EUA, o Estado do Texas era uma república independente, pois havia se separado do território mexicano. As famílias norte americanas que estavam desamparadas economicamente e financeiramente se deslocaram para o Texas para buscar a reconstrução de seus lares ou iniciar nova vida neste território promissor, pois os seus governantes preocuparam-se em colonizar as regiões despovoadas, criando facilidades e vantagens aos seus colonizadores. Em 1836, a população texana não ultrapassava 70 mil habitantes e em 1840 foi para mais de 250 mil. (MARMITT, 1995, p. 17).

$\mathrm{Na}$ data de 26 de janeiro de 1839 foi promulgada a Lei do homestead, assim, surgiu o bem de família. A referida lei procurou fixar o homem à terra, objetivando o desenvolvimento de uma civilização, onde a família pudesse trabalhar e tornar produtiva a aérea de terra que recebeu, bem como viver com 
sua prole sem se preocupar com o risco de desalojamento. Em 1845, o Texas, se incorporou aos EUA. (BUREAU, 1895 apud AZEVEDO, 2002, p. 27-28).

Com o tempo, o instituto do homestead integrou-se na maioria dos estados norteamericanos e também a outros países, nos quais cada um destes adaptou o instituto conforme sua própria legislação. (VENOSA, 2011, p. 393).

\section{ESPÉCIES DE BEM DE FAMÍLIA}

Para o direito brasileiro, nas palavras de Venosa "[...] objeto do bem de família é um imóvel, um prédio, rural ou urbano, onde a família fixa sua residência, ficando a salvo de possíveis e eventuais credores." (VENOSA, 2011, p. 395).

$\mathrm{Na}$ legislação brasileira, existem duas espécies de bem de família: o bem de família legal que surgiu no ano de 1990, disposto na Lei 8.009/90 e o bem de família voluntário ou convencional, introduzido no Código Civil de 2002 (Lei n. 10.406/02), no Livro IV (Do Direito de Família), nos artigos 1.711 a 1.722. (GONÇALVES, 2010, p. 559-560).

Atualmente, a modalidade facultativa, é exclusivamente subsidiária do bem de família obrigatório, eis que o novo Código Civil não atualizou o projeto da matéria, regulando somente o bem de família voluntário, bem como com o advento da Lei n. 8.009/90, o referido instituto bem de família voluntário tem pouca aplicação prática em nosso ordenamento atualmente, portanto, não será abordado no presente estudo.

O bem de família involuntário ou obrigatório ou legal é proveniente da Medida Provisória ${ }^{\circ} 143$, de 1990, após tal Medida, foi promulgada a Lei $\mathrm{n}^{\circ} 8.009$, de 29 de março de 1990, que regula o presente instituto, e o define como norma de cunho de ordem pública, ou seja, imposta pelo próprio Estado em defesa da célula familiar, assim, não tem necessidade de se 
registrar no Registro de Imóveis o imóvel que se trata ser bem de família para que este seja contemplado com a proteção acerca de sua impenhorabilidade, pois o fim social da lei é proteger a vida familiar.

Para Azevedo (2002, p. 167):

[...] o bem de família, como estruturado na lei sob exame, é o imóvel residencial, urbano, ou rural, próprio do casal ou da entidade familiar, e/ou móveis da residência, impenhoráveis por determinação legal.

Como resta evidente, nesse conceito, o instituidor é o próprio Estado, que impõe o bem de família, por norma de ordem pública, em defesa da célula familial. Nessa lei emergencial, não fica a família à mercê de proteção, por seus integrantes, mas é defendida pelo próprio Estado, de que é fundamento.

O objeto do bem de família é o imóvel, urbano ou rural, destinado à moradia da família, não importando a forma de constituição desta, bem como os móveis que guarnecem a residência do seu proprietário ou locatário (melhor, possuidor).

O artigo $5^{\circ}$ da Lei n. 8.009/90 dispõe que "[...] para os efeitos da impenhorabilidade, de que trata esta lei, considera-se residência um único imóvel utilizado pelo casal ou pela entidade familiar para moradia permanente." (BRASIL, 1990).

Azevedo (2002, p. 171) explica:

[...] outro requisito indispensável, além da propriedade do imóvel, é que os membros da família nele residam.

O imóvel é residencial quando servir de local em que se estabeleça uma família, centralizando suas atividades. Ele é, propriamente, o domicílio familiar, em que existe a residência de seus integrantes, em um lugar (elemento objetivo), e o ânimo de permanecer (elemento subjetivo), de estar nesse local, em caráter definitivo.

Neste sentido, Marmitt (1995, p. 27) defende que: 
[...] a impenhorabilidade da Lei 8.009/90 só pode envolver um único imóvel urbano ou rural. Para efeito deste diploma legal considera-se residência uma única propriedade destinada para moradia permanente, excluindo-se, assim, do benefício da impenhorabilidade as casas de veraneio ou lazer e similares.

Na mesma linha de raciocínio, Credie (2010, p. 12-13) evidencia que:

[...] em segundo lugar, que se trate de residência efetiva do grupo ou núcleo familiar, incluído aí o habitante singular. Única e permanente, diz o art. $5^{\circ}$ da Lei n. 8.009/90. Nos arts. 1.712 e 1.717 do CC também se expressa essa ideia de destinação exclusiva.

A melhor interpretação que se tira destas normas é a de que as pessoas estejam alojadas no imóvel com ânimo de permanência nele, como lar, como sede da família. Domicílio, no sentido do art. 70 do Código Civil, que é o lugar onde a pessoa se estabelece como residente e em definitivo.

Mesmo que seus integrantes, periodicamente, estejam em lugar diverso (por exemplo, profissionais que viajam estudos ou cursos que se frequentam dentro ou fora do país, residência episódica em outro local etc.), o que determina esta efetividade é o vínculo do grupo ou da pessoa com a habitação, sem a constituição da moradia definitiva alhures. $[\ldots]$

À hipótese de família multi ou pluridomiciliada, que tenha residências onde alternativamente viva (art. 71 do CC), responde a Lei n. 8.009 com a indicação, pelo proprietário, de apenas uma das casas utilizadas, sob pena de se tornar impenhorável a de valor menor do acervo.

$[\ldots]$

A casa de campo ou a de praia excluem-se da inexcutibildade, por lhes faltarem esses requisitos básicos, desde que não se tenham tornado residência definitiva.

A lei, portanto, objetiva a proteção da família do devedor 
e não o devedor em si. O referido artigo supracitado exige, também, como requisito para a caracterização do bem de família, ser "moradia permanente" no imóvel. Desta forma, as pessoas devem ocupar o imóvel residencial com ânimo de permanência definitiva nele.

\section{PENHORA DO IMÓVEL RESIDENCIAL (BEM DE FAMÍLIA LEGAL) DO FIADOR NO CONTRATO DE LOCAÇÃO - A (IN) CONSTITUCIONALIDADE A PARTIR DA DOUTRINA PERANTE OS PRINCÍPIOS DE DIREITOS FUNDAMENTAIS}

A Lei n. 8.009/90 tem por objetivo proteger o imóvel residencial da penhorabilidade, porém, o artigo $3^{\circ}$ dispõe de exceções. No presente trabalho, analisamos a exceção do inciso VII da referida Lei.

A (in)constitucionalidade desta penhora começou a ser questionada a partir do advento da Emenda Constitucional $n^{\circ}$ 26, de 14 de fevereiro de 2000, a qual incluiu entre os direitos sociais previstos no art. $6^{\circ}$ da CRFB o direito à moradia, especificadamente sobre a recepção desta ou não pelo inciso VII acrescido pela Lei 8.245/91 no artigo $3^{\circ}$ da Lei 8.009/90.

O Supremo Tribunal Federal, em 2005, declarou a inconstitucionalidade desta penhora, através de decisão monocrática nos Recursos Extraordinários de no 352.940-4 e no 449657. (BRASIL, STF, 2005).

Entretanto, no ano de 2006, o STJ declarou a constitucionalidade da penhora do imóvel residencial do fiador no contrato locação, tendo como fundamento que o artigo $3^{\circ}$, inciso VII da Lei n. 8.009/90 não afronta o direito à moradia, disposto no art. $6^{\circ}$ da Constituição Federal, conforme julgamento do Recurso Extraordinário de $n^{\circ}$ 407.688-8. (BRASIL, 2006). 
Para corroborar com a referida decisão pela constitucionalidade da penhora, na data de 13 de agosto de 2010, houve Repercussão Geral sobre o referido tema no Recurso Extraordinário n. 612.360, de relatoria da Ministra Ellen Gracie (BRASIL, 2010).

No ano de 2015, o STJ emitiu súmula a favor também da referida penhora. Vejamos: "Súmula 549: É válida a penhora de bem de família pertencente a fiador de contrato de locação".

Atualmente, o entendimento se mantém tanto nos Tribunais Superiores (STF e STJ), bem como nos Tribunais Estaduais, entretanto, a doutrina diverge sobre o assunto.

\subsection{Posicionamentos acerca da constitucionalidade da penhora}

O emprego do inciso VII trazido pelo artigo 82 da Lei $\mathrm{n}$. $8.245 / 91$ ao artigo $3^{\circ}$ da Lei n. 8.009/90 teve por objetivo fomentar o mercado imobiliário no que tange às relações de locação. (TUCCI, 2003, p. 14).

Para Tucci (2003, p. 15):

[...] a rigor, a consequência dessa modificação foi a de facilitar o direito à moradia, sobretudo porque permite que as pessoas de renda menos avantajada, que têm dificuldades para garantir o cumprimento do contrato de locação, possam apresentar um fiador que assuma a respectiva responsabilidade.

O direito à moradia é norma de eficácia limitada ou reduzida, a qual possui aplicação indireta, mediata e reduzida, eis que somente irão refletir-se no mundo jurídico após uma normativa posterior que lhes ofereça eficácia, ou seja, necessita de regulação própria e específica para que tenha possibilidade de gerar efeitos no plano da realidade jurídica. (TUCCI, 2003, p. 17-19).

As normas programáticas não permitem que os cidadãos as 
invoquem imediatamente após a entrada em vigor da Constituição, assim deve-se pedir aos tribunais o seu cumprimento só por si. (MIRANDA, 1991, p. 245 apud TUCCI, 2003, p. 18).

Segundo Ferreira e Fernandes (2000, p. 202 apud TUCCI, 2003, p. 19):

[...] todas as normas constitucionais são dotadas de eficácia jurídica, uma vez que têm o condão de revogar a ordem jurídica incompatível com o seu texto. Todavia, poderá a norma não ter eficácia social, na hipótese de ser inaplicável a situações concretas. E isso se verifica com o direito à moradia, porquanto a principal função da norma constitucional que o garante é a de 'representar importante diretriz a orientar o Poder Público para implementação de políticas que assegurem esse novo direito.

$\mathrm{O}$ artigo 23, inciso IX da CF, dispõe que a União, os Estados, o Distrito Federal e os Municípios possuem competência comum para promover programas de construção de moradias e melhorias das condições habitacionais. (TUCCI, 2003, p. 19).

Para Credie (2010, p. 21-22):

[...] não há discrepância alguma entre o texto da Lei n. 8.009/90, no que se interpreta finalística ou teleologicamente, e as demais normas constitucionais, sobretudo aquelas que apontam para a dignidade da pessoa humana (art. $1^{\circ}$, III), para a solidariedade social (art. $3^{\circ}$, I), para a isonomia (art. $5^{\circ}$, caput), e para a formação de uma sociedade livre, sadia e desenvolvida (art. $3^{\circ}$, I a IV), como objetivos do Estado.

Além disso, o bem de família preexistente na legislação civil, deixado de lado o seu necessário ato de criação facultativa, em nada era diferente do atual obrigatório, tanto na essência como nas suas consequências práticas.

Existia antes o bem de família, só que poucos o usavam.

Há, implícita na nova ideia legal do bem de família, uma revisão axiológica ou de valores: o interesse comum não 
pode ficar na dependência da vontade isolada do indivíduo. $[\ldots]$

Penso defluir daí a sua indiscutível constitucionalidade.

A regra da penhorabilidade do bem de família do fiador favorece o direito à moradia das pessoas interessadas em locar bem imóvel urbano. Com a permanência desta penhora, aumenta-se a oferta de imóveis oferecidos à locação, assim, de uma forma indireta favorece o exercício do direto à moradia de pessoas que não são proprietárias de imóvel e necessitam de bens de outras pessoas (dos proprietários) para morar, sendo que se ocorrer a exclusão do contrato de fiança pode haver diminuição da oferta de imóveis predispostos à locação, bem como também, pode ocorrer de o proprietário requerer outras espécies de garantias, as quais podem ser mais onerosas. Observa-se que, assim, dificultaria o papel do Estado de promover o direito à moradia. (DEMÓCRITO, 2008).

Quanto ao princípio da isonomia tenha-se que não é aplicável à penhora do imóvel residencial do fiador no contrato de locação decorrente de dívidas de aluguéis, visto que, o locatário tem uma posição diferente do fiador perante o contrato de locação, pois, a lei o quis proteger da penhora,e, assim estabeleceu a impenhorabilidade como regra geral; outra posição é a situação do fiador, o qual não é parte na locação. (DEMÓCRITO, 2008).

Diniz (2009 apud JUNQUEIRA, ROQUE, 2009) observa que:

[...] se assim é, parece-nos, ante o caráter de norma especial do art. 82 da Lei n. 8.245/91 e do art. $3^{\circ}$, VII, da Lei n. 8.009/90, inconstitucionalidade não há, tendo em vista que a moradia é direito social tutelado pelo Estado e não pelo particular e que o fiador, ao garantir dívida locatícia, assumiu tal risco e que as obrigações do locatário e do fiador são diferentes apesar de terem a mesma causa: o contrato de locação. 
A fiança visa facilitar a concretização das locações. Logo, alterar a lei para que o imóvel residencial do fiador não seja mais penhorado para fins de honrar os encargos da locação, iria inviabilizar a fiança. No entanto, este não é o objetivo da lei que observa facilitar a locação e não impedí-la. (JUNQUEIRA, ROQUE, 2009).

Azevedo (2002, p. 198-199) entende que "[...] a fiança locatícia apresenta natureza jurídica diversa, pois estabelece a vinculação de um bem específico, oferecido em garantia".

Souza (2004, p. 272-274 apud DE CARLI, 2009, p. 126) defende a constitucionalidade do inciso VII, dizendo que:

[...] na realidade, a lei visou a proteger e estimular o mercado imobiliário e facilitar a realização dos contatos locatícios. [...] Com a referida norma, facilita-se o direito à moradia não só do locatário, mas da coletividade, pois se propicia com ela o aumento de moradas para a população, sem a necessidade de aquisição de um imóvel. Assim, poder-se-ia falar em recepcionalidade da norma legal se fosse estabelecida a penhorabilidade do imóvel residencial do fiador - ainda que seu único imóvel - para contratos de locação de caráter exclusivamente residencial.

O bem fica gravado por um contrato real de penhor ou de verdadeira hipoteca, de acordo com o artigo $38, \S 1^{\circ}$ da Lei n. $8.245 / 91$, para que assim, perante a estas providências registrais se tenha um direito real sobre coisa alheia. O locador tem direito de executar o bem específico dado em penhor. (SOUZA, 2004 apud DE CARLI, 2009, p. 126).

De acordo com Maluf (2010, p.19-34): “[...] o termo caução é sinônimo de garantia. Daí falar em caução real, no caso de hipoteca, penhor, anticrese, caução de títulos e também no caso de depósito, como também em caução pessoal, que corresponde à garantia fidejussória (fiança)".

Devido à existência de um contrato em que o bem do fiador 
se torna penhorável, considera-se um ato jurídico perfeito, o qual estende sua validade a terceiros, ou seja, com efeitos erga omnes, posto a isto, não há como falar na desconstituição desta penhora por ser bem de família. (AZEVEDO, 2002, p. 199).

\subsection{Posicionamentos acerca da inconstitucionalidade da penhora}

Hoje, a penhora do bem de família do fiador no contrato de locação é considerada constitucional de acordo com o Supremo Tribunal Federal, como já fora visto acima. Porém, existe posição minoritária a qual entende que esta penhora é inconstitucional devido ferir princípios e direitos fundamentais dispostos na Constituição Federal da República Federativa Brasileira como: princípio da isonomia, princípio da dignidade da pessoa e o direito a moradia, bem como o princípio da função social dos contratos previsto no Código Civil.

Tartuce (2009, p. 419) explicita que: "[...] uma posição minoritária entende ser previsão inconstitucional, por violar a isonomia (art. $5^{\circ}$, caput, da CF/1988) e a proteção da dignidade humana. (art. 1. , III, da CF/1988)".

O princípio da isonomia está disposto no artigo $5^{\circ}$ da Constituição Federal (BRASIL, 1988), o qual dispõe que "todos são iguais perante a lei, sem distinção de qualquer natureza, garantindo-se aos brasileiros e aos estrangeiros residentes no País a inviolabilidade do direito à vida, à liberdade, à igualdade, à segurança e à propriedade [...]”"

Segundo Bulos (2010, p. 538), “[...] a igualdade constitucional mais do que um direito é um princípio, uma regra de ouro, que serve de diretriz interpretativa para as demais normas constitucionais".

O referido autor $(2010$, p. 539, grifo do autor) salienta que existem duas espécies de isonomia no atual ordenamento: 
[...] a igualdade jurídico-formal, presente entre nós desde o Império, é decretada pelo uso da expressão 'perante lei'.

Assim, o texto de 1998 a consagra quando diz que 'todos são iguais perante a lei, sem distinção de qualquer natureza' (art. $5^{\circ}$, caput, $1^{\text {a }}$ parte).

$[\ldots]$

Igualdade material, portanto, é a concretização da própria isonomia formal, que sai o papel para se realizar na prática.

De acordo com Tartuce (2009, p. 419):

[...] o devedor principal (locatário) não pode ter o seu bem de família penhorado, enquanto o fiador (em regra, devedor subsidiário - art. 827 do CC) pode suportar a constrição. A lesão à isonomia e à proporcionalidade reside no fato de a fiança ser um contrato acessório, que não pode trazer mais obrigações do que o contrato principal (locação). Em reforço, há desrespeito à proteção constitucional da moradia (art. $6^{\circ}$ da CF/1988), uma das exteriorizações do princípio de proteção a dignidade da pessoa humana.

\section{Gagliano e Rodolfo Filho (2012, p. 408) ensinam:}

[...] à luz do Direito Civil Constitucional - pois não há outra forma de pensar modernamente o Direito Civil -, parece-me forçoso concluir que este dispositivo de lei viola o princípio da isonomia insculpido no art. $5 .^{\circ}$ da $\mathrm{CF}$, uma vez que trata de forma desigual locatário e fiador, embora as obrigações de ambos tenham a mesma causa jurídica: o contrato de locação.

\section{Para Marmitt (1995, p. 95):}

[...] o inciso VII do art. $3^{\circ}$ da Lei 8.009/90 revela-se injusto para com o fiador, colocando-o em grau de inferioridade quanto ao locatário. Referido inciso foi acrescido pelo art. 82 da atual Lei do Inquilinato, tornando penhorável o imóvel residencial do fiador e de sua família, por dívida relativa à fiança dada em pacto locacional. Executando o fiador, são penhorados os seus bens, inclusive seu imóvel residencial. 
Entretanto, não se poderá usar de direito regressivo contra o afiançado, para dele penhorar os mesmos bens, que são protegidos pela Lei n. 8.009.90 com impenhorabilidade.

\section{Alberton (2003, p. 123-124) salienta que}

[...] se há uma desigualdade de tratamento entre o devedor principal e fiador, não aplicar o art. 82 da Lei 8.245/91 não é negar-lhe vigência, mas afirmar a sua invalidade por trazer como consequência a inobservância o princípio constitucional da isonomia previsto no caput do art. $5 .^{\circ} \mathrm{da} \mathrm{CF}$.

Lauria Tucci; Tucci (1989, p. 41 apud ALBERTON, 2003 , p. 125) referenciam que "[...] impondo-se à legislação ordinária amoldar suas normas às preceituações constitucionais, nela não pode haver lugar para o estabelecimento de discriminações ou privilégios, quaisquer que sejam, isto é, de desigualdade entre iguais".

A interpretação de inconstitucionalidade do art. $3 .^{\circ}$, VII, da Lei n.8.009/90 possui relação direta com o princípio da função social dos contratos. Por este princípio, os contratos devem ser interpretados de acordo com o contexto da sociedade, pois integram um regramento de ordem pública, bem como com fundamento constitucional, o qual se pode visualizar nos artigos 421e 2.035, parágrafo único do CC, bem como da tríade: dignidade; solidariedade e igualdade. (TARTUCE, 2009, p. 420).

Frisa-se que, o mesmo princípio encontra fundamento na função social da propriedade, a qual deve ser compreendida em sentido amplo, de acordo com o que dispõe a CRFB em seus artigos art. $5^{\circ}$, incisos XXII e XXIII e art.170, inciso III. (BRASIL, 1988).

De acordo com o Fórum Nacional de Reforma Urbana (2008):

[...] a função social da propriedade é um princípio que está vinculado a um projeto de sociedade mais igualitária, isso 
se deve em razão de submeter o acesso e o uso da propriedade ao interesse coletivo; portanto a propriedade urbana cumpre a sua função social quando destinada para satisfazer as necessidades dos habitantes da cidade. Os parâmetros para a satisfação destas necessidades são os componentes do direito às cidades sustentáveis, como o direito à moradia digna, o acesso a terra urbana, à saúde, educação, ao meio ambiente, ao transporte e aos serviços públicos, à infra-estrutura urbana, ao saneamento ambiental, ao trabalho, ao lazer e a cultura.

Souza (2005, p. 13 apud DE CARLI, 2009, p.101) explica que a função social do contrato sob a ótica sociológica consiste "[...] em colocar o contrato a serviço da construção da dignidade do homem, da eliminação da miséria, das desigualdades sociais, e da melhor distribuição de renda".

Para Lenza (2011, p. 1066), “[...] partindo da ideia de dignidade da pessoa humana (art. 1. $\left.{ }^{\circ}, \mathrm{III}\right)$, direito à intimidade $\mathrm{e}$ à privacidade (art. 5. $\left.{ }^{\circ}, \mathrm{X}\right)$ e de ser a casa inviolável (art. 5. ${ }^{\circ}$, $\mathrm{XI}$ ), não há dúvida de que o direito à moradia busca consagrar o direito à habitação digna e adequada ".

Observa Nunes $(2009$, p. 26) que "é difícil a fixação semântica do sentido de dignidade, isso não implica que ela possa ser violada. Como dito, ela é a primeira garantia das pessoas e a última instância de guarida dos direitos fundamentais."

Segundo Gagliano e Rodolfo Filho (2010, p. 65, grifo do autor):

[...] por se tratar de cláusula geral, de natureza principiológica, a sua definição é missão das mais árduas, muito embora arrisquemo-nos em dizer que a noção jurídica de dignidade traduz um valor fundamental de respeito à existência humana, segundo as suas possibilidades e expectativas, patrimoniais e afetivas, indispensáveis à sua realização pessoal e à busca da felicidade.

Mais do que garantir a simples sobrevivência, este princí- 
pio assegura o direito de se viver plenamente, sem quaisquer intervenções espúrias - estatais ou particulares - na realização desta finalidade.

Não há como separar a moradia da personalidade do indivíduo, pois, além de servir de abrigo, a ela se encontram atrelados outros significantes, como a vida e a dignidade humana. (DE CARLI, 2009, p. 9).

De Carli (2009, 100-101) ressalta que:

[...] numa relação contratual, subsumida num tipo de contrato, deve-se primar pela justiça, consubstanciada na máxima de agir conforme os ditames da lealdade, da eticidade, da probidade, da solidariedade e da igualdade substancial. Desta forma, a relação jurídico-contratual não só estará cumprindo a sua função social, como também colocando o homem de carne e osso no centro desta relação: trata-se da consagração da dignidade humana.

$\mathrm{Na}$ esteira desse entendimento, reconhece-se que, na hipótese de conflito entre o direito humano fundamental à moradia do fiador e o direito de crédito do locador - por exemplo, é indiscutível que deve preponderar aquele, visto garantir não apenas o teto do fiador e de sua família - que já seria motivo suficiente para prevalecer em face do direito de crédito -, mas preserva outros valores, como a dignidade humana.

Alberton (2003, p. 127) frisa que “[...] fiador é apenas um garantidor do afiançado e não deve ter afastada a garantia à impenhorabilidade do seu único bem imóvel utilizado para moradia como garantia do direito social à manutenção da moradia."

O direito à moradia, para Silva (2008, p. 314):

[...] significa ocupar um lugar como residência; ocupar uma casa, apartamento etc., para nele habitar. No 'morar' encontramos a ideia básica de habitualidade no permanecer ocupando uma edificação, o que sobressai com sua correlação com o residir e o habitar, com a mesma conotação de permanecer ocupando um lugar permanente. $\mathrm{O}$ direito 
à moradia não é necessariamente direito à casa própria. Quer-se que se garanta a todos um teto onde se abrigue com a família de modo permanente, segundo a própria etimologia do verbo morar, do latim 'morari', que significa demorar, ficar.

O conteúdo do direito à moradia envolve não só a faculdade de ocupar uma habitação. Exige-se que seja uma habitação de dimensões adequadas, em condições de higiene e conforto e que preserve a intimidade pessoal e a privacidade familiar $[\ldots]$.

Salienta-se que este direito possui duas faces: a negativa e a positiva, a primeira demonstra que o cidadão não pode ser privado de ter, bem como de ser impedido de conseguir uma moradia, no que tange à abstenção do Estado ou de terceiros, a segunda consta do direito de se ter uma moradia digna e adequada advinda do poder estatal, ou seja, o direito à moradia é realizado através do Estado. (SILVA, 2008, p.315).

Alberton (2003, p. 108) explica que:

[...] embora pareça temerário colocar em nível de direito/ princípio fundamental a proteção à moradia como forma de preservação da dignidade da pessoa humana, impõe-se ter presente que a valorização do homem tem seu suporte na possibilidade de permitir que ele exerça a sua humanidade com garantia de liberdade e de inclusão social. Aliás, a inclusão não se caracteriza apenas na possibilidade de lhe dar condições de educação, de emprego, de saúde, mas também, entendo, de manter-lhe teto próprio que lhe sirva de residência.

Para Bester (2005 apud MARCON, 2006, p. 58), o direito a moradia vem ao encontro do princípio da dignidade da pessoa humana:

[...] moradia resguarda a dignidade da pessoa diretamente, no caso de proteção de um espaço para morar e manter 
a privacidade, como também indiretamente, pela manutenção da possibilidade de subsistência da pessoa, na hipótese do asseguramento da pequena propriedade rural. Lamentavelmente, veem-se no Brasil algumas decisões judiciárias que possibilitam a penhora do bem de família nos casos de fiança dada em contratos locatícios, um nítido desfavorecimento da proteção da dignidade da pessoa humana em prol da proteção do patrimônio.

De Carli (2009, p. 111) acredita que:

[...] vale repisar que o bem de família, assegurado legalmente ou por meio de ato de vontade, consubstancia efetivo instrumento de realização do direito humano fundamental à moradia. De fato, sua ratio está calcada substancialmente na dignidade da pessoa humana e em seu pleno desenvolvimento. A propriedade defendida, no caso do bem de família, não consubstancia direito fundamental autônomo, mas uma via instrumental para a realização do direito humano fundamental à habitação [...] Admitir que um direito de crédito, decorrente de obrigação assumida em contrato de fiança, por conta de garantia em contrato de locação, tenha força de, numa execução, excutir o único bem do fiador é fazer letra morta da Constituição e desconsiderar a essencialidade do direito humano fundamental à moradia.

Aina (2001 apud MARCON, 2006, p. 59) afirma que a moradia é uma necessidade premente de todo ser humano:

[...] todos precisamos de um local para nos abrigarmos das intempéries, descansarmos de nossa labuta, abrigarmos nossa família, guardamos nossos bens, sentirmo-nos seguros, enfim, garantirmos a nossa sobrevivência com dignidade. Um lar significa paz de espírito e motivo de profunda felicidade para os indivíduos [...] a moradia é um valor de conceito amplo que envolve a garantia de um abrigo digno, salubre e que promova o bem-estar de seus ocupantes, de forma a concretizar a existência com dignidade dos indivíduos. Neste aspecto, encontra vertentes no direito à vida, no direito à saúde, na proteção da família [...].

O sentido social da Lei n. 8.009/90 é buscar a garantia de um 
teto para cada pessoa, eis que a referida Lei criou o espírito protetor da família humana, em que lhes é reservado bens essenciais ao seu desenvolvimento, bem como tange na adequação de seus membros à realidade social. (NUNES, 2001, p. 148).

Nunes (2001, p. 149), ainda, salienta que:

[...] o imóvel residencial é realmente uma necessidade fundamental no desenvolvimento da pessoa humana.

Trata-se de necessidade primária para o gênero humano. A raposa tem a toca, e, as aves, os ninhos. E o ser humano necessita de um abrigo que o proteja das intempéries e de seus naturais inimigos.

Branco (2009, p. 490) explica que:

[...] o direito à privacidade teria por objeto os comportamentos e acontecimentos atinentes aos relacionamentos pessoais em geral, às relações comerciais e profissionais que o indivíduo não deseja que se espalhem ao conhecimento público. $\mathrm{O}$ objeto do direito à intimidade seriam as conversações e os episódios ainda mais íntimos, envolvendo relações familiares e amizades mais próximas.

No entendimento de Silva (1998, p. 49-50):

[...] sentimos a necessidade de preservar a nossa intimidade pela vergonha de expor aos outros as nossas fraquezas, as nossas imperfeições; pelo receio de assumir publicamente o que fazemos, falamos ou pensamos reservadamente e de um juízo negativo a nosso respeito;

$[\ldots]$

Essa inibição que naturalmente experimentamos diante das outras pessoas, muitas vezes calada em sentimento de insegurança ou de incerteza a respeito das nossas qualidades pessoais, da nossa capacidade de realizar e da limitação dos nossos conhecimentos, poderia sufocar de forma significativa o desenvolvimento das nossas potencialidades, se todos os passos que tivéssemos de dar para o nosso amadurecimento, desde o pensar e do sentir até a sua exterioriza- 
ção em atos ou atitudes, se dessem necessariamente sob a vigilância crítica e eventualmente severa de todos.

$[\ldots]$

Por isso que uma certa dose de reserva e de recolhimento é de importância fundamental para o desenvolvimento saudável da personalidade.

Fachin (2003, p. 267 apud DE CARLI, 2009, p. 9) expressa que "[...] a casa é, cada vez mais, o centro da existência. O lar oferece, num mundo duro, um abrigo, uma proteção, um pouco de calor humano".

A segunda geração de direitos fundamentais surgiu no século XIX através das consequências da Revolução Industrial, as quais eram advindas das péssimas situações e condições de trabalho, bem como desigualdades sociais. Assim, surgiram os direitos econômicos, sociais e culturais, os quais correspondem aos direitos de igualdade. (DE CARLI, 2009, p. 62).

$\mathrm{O}$ direito à moradia constitui-se inegavelmente em direito social, encontrando abrigo perfeito no rol dos direitos de segunda dimensão ou geração. (AINA, 2001, apud MARCON, 2006, p. 55).

Não cabe mais o argumento de que o direito à moradia por ser considerado norma programática estaria sujeito à regulamentação por normas infraconstitucionais, é o caso do inciso VII do art. $3^{\circ}$ da Lei n.8.009/90, eis que tais normas tem aplicação imediata pela teoria da eficácia horizontal dos direitos fundamentais. (TARTUCE, 2009, p.421).

Lenza (2011, p. 954) ensina acerca das duas teorias da aplicabilidade da eficácia dos direitos fundamentais:

- eficácia indireta ou mediata - os direitos fundamentais são aplicados de maneira reflexa, tanto em uma dimensão proibitiva e voltada para o legislador, que não poderá editar lei que viole direitos fundamentais, como, ainda, posi- 
tiva, voltada para que o legislador implemente os direitos fundamentais, ponderando quais devam aplicar-se às relações privadas;

- eficácia direta ou imediata - alguns direitos fundamentais podem ser aplicados às relações privadas sem que haja a necessidade de 'intermediação legislativa' para a sua concretização.

Barroso (2011, p. 395) observa que "[...] o ponto de vista da aplicabilidade direta e imediata afigura-se mais adequado para a realidade brasileira $[\ldots]$ "..

Alberton (2003, p. 119-120) frisa que:

[...] a presunção de uma realidade que não está expressa contratualmente. Supõe-se que o fiador, ao aceitar ser fiador do locatário tem ciência de que seu único bem imóvel está sujeito à execução por eventual inadimplemento. Mera suposição, porque raramente no contrato está expressa a indicação do imóvel como garantia.

[...]os contratos de locação são efetivos contratos por adesão, com termos já impressos, padronizados, onde o fiador assina, abre mão do direito de ordem, assume obrigação de forma solidária e não tem expressa a advertência de que o seu imóvel residencial está sujeito à garantia de dívida que eventualmente ocorra por inadiplemento do afiançado.

De Carli (2009, p. 162) salienta que na questão desta penhora deve-se:

[...] levar em consideração valores fundamentais, como a dignidade humana, a família e o mínimo existencial, bem como o contexto social nacional, no qual $11 \%$ da população são analfabetos, sem esquecer dos analfabetos funcionais, que atingem o patamar de $26 \%$ dos habitantes, os quais conseguem ler, mas não têm a compreensão necessária do que lêem.

A referida doutrinadora (2003, p. 162) salienta que: “[...] o art. $3^{\circ}$, inciso VII, da Lei n. 8.009/90, tem validade constitu- 
cional condicionada, isto, será constitucional desde que incida somente sobre o bem excedente do fiador e jamais sobre aquele que lhe serve de abrigo".

Alberton (2003, p. 126) entende que:

[...] portanto, em que pese a disposição expressa da Lei 8.245 , merece ser afastada a penhorabilidade do único bem imóvel residencial do fiador, desde que essa circunstância não seja apenas alegada, mas comprovada. Além disso é necessário que o fiador não tenha indicado expressamente o imóvel como garantia.

Com base no exposto, vale a pena conferir os 6 (seis) Projetos de Leis, em trâmite na Câmara dos Deputados atualmente acerca desta penhora ( alguns com ressalvas e exceções e também temos os que requerem a exclusão de forma total desta): PL-1358/2011, PL - 987/2011, PL - 6155/2013, 6096/2013, PL - 2976/2015, 10130/2018.

\section{CONCLUSÃO}

Por meio do presente estudo, verificou-se que, apesar do entendimento pela constitucionalidade da penhora do imóvel residencial (bem de família legal) do fiador no contrato de locação já está consolidado desde o ano de 2006, inclusive com Repercussão Geral em Recurso Extraordinário, observamos que na doutrina ainda há discussão acerca de de sua constitucionalidade.

O posicionamento doutrinário que entende pela constitucionalidade da matéria observa que este tipo de penhora não fere os princípios e direitos fundamentais, pelos seguintes fundamentos: emprego do inciso VII realizado ao artigo $3^{\circ}$ da Lei n. 8.009/90, que teve por objetivo fomentar o mercado imobiliário no que tange às relações de locação, assim, facilitando o direito à moradia; o direito à moradia por ser um 
direito social estaria disposto na Constituição como norma programática e, nesse sentido, dependeria de regulamentação própria e específica para poder ser aplicado na prática e assim gerar efeitos. Portanto, cabe ao Estado promover este direito de acordo com ao artigo 23, inciso IX da CRFB; o interesse comum prevalece sobre o interesse particular, bem como encontra-se baseado na liberdade de escolha do fiador (de aderir ou não ao contrato de fiança), assim, não cabe a aplicação do princípio e direito da isonomia, eis que o fiador não é parte da locação e encontra-se em um patamar diferente do locatário. A lei quis proteger o locatário e que a fiança facilitasse as locações, eis que se houver extinção do contrato, isto irá onerar garantias e, assim, ferir o direto à moradia, bem como contrato em que o bem do fiador se torna penhorável, de modo que isso é considerado um ato jurídico perfeito.

A sua inconstitucionalidade encontra-se na violação ao princípio da isonomia, ao princípio da dignidade da pessoa, ao direito à moradia e ao princípio da função social dos contratos previsto no Código Civil.

Depreende-se que o fiador é tratado de forma desigual perante o locatário, eis que o contrato de fiança é contrato acessório e possui mais obrigações do que o contrato do locatário, contudo não deveria, já que o contrato acessório não pode ter mais obrigações do que o contrato principal, bem como as obrigações de ambos, tanto locatário como o fiador possuem a mesma causa jurídica: o contrato de locação.

$\mathrm{O}$ direito à moradia e o princípio da dignidade da pessoa se complementam, eis que o princípio da dignidade da pessoa abrange os direitos fundamentais inerentes a esta, como: direito à vida, à imagem, à intimidade e outros, assim, sendo de extrema importância no desenvolvimento da personalidade da pessoa, bem como às relações familiares que se solidificam 
no lar. É no lar que o ser humano se refugia das intempéries da vida, é no lar que ele constrói a base familiar, ou seja, se está diante de um direito fundamental inerente ao ser humano, eis que este também é uma forma de preservar sua dignidade perante ao Estado e a outros cidadãos.

Observamos também que a referida penhora fere o princípio da função social do contrato, pois por este princípio, os contratos devem ser interpretados de acordo com o contexto da sociedade, haja vista que é um regramento de ordem pública e um fundamento constitucional.

No contrato de locação, a cláusula acerca da penhora do imóvel residencial não vem disposta neste, é uma cláusula intrínseca ao fiador e, desta forma, o mesmo fica em desvantagem por não saber que seu imóvel residencial pode ser penhorado, caso o locatário não pague os aluguéis. $\mathrm{O}$ benefício de ordem já vem incluído no contrato com a ressalva de "renúncio o benefício de ordem" sem ao menos dar a chance ao fiador de ter este benefício que a maioria das vezes é desconhecida por ele, pois, a maioria das pessoas tornam-se fiadoras de conhecidos por generosidade e não sabem muitas vezes o que estão assinando por falta de conhecimento e aviso.

Com o referido estudo, verificamos que conforme demonstrado nas fundamentações e a aplicação de princípios e direitos fundamentais é inconstitucional, a nosso ver, a penhora do imóvel residencial (bem de família legal) do fiador no contrato de locação.

Por fim, frisa-se que, não se buscou no presente trabalho esgotar o assunto, uma vez que o mesmo poderá ser objeto de estudo e discussões posteriores, tendo em vista sua amplitude e divergências. 


\section{REFERÊNCIAS}

ALBERTON, Genacéia da Silva. Pela ineficácia da penhora. In: CRUZ E TUCCI, José Rogério (Coord.). A penhora e o bem de familia do fiador da locação. São Paulo: Revista dos Tribunais, 2003. Parte II, p. 101-131.

AZEVEDO, Álvaro Villaça. Bem de família legal: comentários à Lei 8.009/90. 5. ed. rev. ampl. e atual. São Paulo: Revistas dos Tribunais, 2002.

BARROSO, Luís Roberto. Curso de direito constitucional contemporâneo: os conceitos fundamentais e a construção do novo modelo. 2. ed. São Paulo: Saraiva, 2011.

BRANCO, Paulo Gustavo Gonet. Direitos fundamentais em espécie. In: BRANCO, Paulo Gustavo Gonet; COELHO, Inocêncio Mártires; MENDES, Gilmar Ferreira. Curso de direito constitucional. 4. ed. rev. e atual. São Paulo: Saraiva, 2009. cap. 6, p. 393-460.

BRASIL. Constituição (1988). Constituição da República Federativa do Brasil. Brasília, DF: Senado Federal, 1988. Disponível em: <http://www.planalto.gov.br/ccivil_03/ constituicao/constituicao.htm>. Acesso em: 14 maio 2018.

Lei n. 8.009/90, de 29 de março de 1990. Dispõe sobre a impenhorabilidade $\overline{\text { do bem }}$ de família. Disponível em: < http://www.planalto.gov.br/ccivil_03/leis/18009. htm $>$. Acesso em: 14 maio 2018.

Lei ${ }^{\circ} 10.406$, de 10 de janeiro de 2002. Institui o código civil. Disponível em: < http://www.planalto.gov.br/ccivil_03/leis/2002/110406.htm>. Acesso em: 14 maio 2018.

. Recurso Extraordinário n449657, decisão monocrática, Antonio Elpídio Moreira e outro (a/s) e Espólio de Antônio Marques. Relator: Min. Carlos Velloso. Brasília, DF, 27 de maio de 2005. Disponível em: <http://www.stf.jus.br/portal/jurisprudencia/listarJurisprudencia.asp?s1=\%28RE $\% 24 \% 2 \mathrm{ESCLA} \% 2 \mathrm{E}+\mathrm{E}+449657 \% 2 \mathrm{ENU}-$ $\mathrm{ME} \% 2 \mathrm{E} \% 29+\mathrm{NAO}+\mathrm{S} \% 2 \mathrm{EPRES} \% 2 \mathrm{E} \&$ base=baseMonocraticas\&url=http://tinyurl. com/a9bd277>. Acesso em: 28 maio 2018.

. Repercussão geral em recurso extraordinário n 612.360, Nágela dos Santos Silva e Anastase Pandelis Gadzanis. Relatora: Min. Ellen Gracie. Brasília, DF, 13 de agosto de 2010. Disponívelem: $<$ http://www.stf.jus.br/portal/jurisprudencia/listarJurisprudencia.asp?s $1=\% 28 \mathrm{RE} \% 24 \% 2 \mathrm{ESCLA} \% 2 \mathrm{E}+\mathrm{E}+612360 \% 2 \mathrm{ENUME} \% 2 \mathrm{E} \% 29+\mathrm{OU}-$ +\%28RE\%2EPRCR\%2E+ADJ2+612360\%2EPRCR $\% 2 \mathrm{E} \% 29 \&$ base=baseRepercussao\&url=http://tinyurl.com/b4ebcxn>. Acesso em: 28 maio 2018.

. Súmula 549. É válida a penhora de bem de família pertencente a fiador de

contrato de locação, segunda seção, Brasília, DF, 14 de outubro de 2015. Disponível em: $\quad<$ http://www.stj.jus.br/SCON/sumulas/doc.jsp?processo=549\&b=SUMU\&p=-

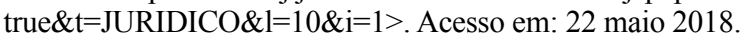

. Supremo Tribunal Federal. Recurso extraordinário n 352940, decisão monocrática, Ernesto Gradella Neto e outra e Teresa Cândida dos Santos Silva. Relator:Min. Carlos Velloso. Brasília, DF, 25 de abril de 2005. Disponível em: $<$ http://www.stf.jus.br/portal/jurisprudencia/listarJurisprudencia.asp?s1=\%28RE $\% 24 \% 2 \mathrm{ESCLA} \% 2 \mathrm{E}+\mathrm{E}+352940 \% 2 \mathrm{ENU}-$ $\mathrm{ME} \% 2 \mathrm{E} \% 29+\mathrm{NAO}+\mathrm{S} \% 2 \mathrm{EPRES} \% 2 \mathrm{E} \&$ base=baseMonocraticas\&url=http://tinyurl. com/a3c37x8>. Acesso em: 28 maio 2018. 
. Supremo Tribunal Federal. Recurso extraordinário n407.688-8, sessão plenária, Michel Jacques Peron e AntonioPecci. Relator: Min. Cezar Peluso. Brasília, DF, 08 de fevereiro de 2006. Disponível em: <http:/www.stf.jus.br/portal/jurisprudencia/listarJurisprudencia.asp?s1=\%28RE $\% 24 \% 2 \mathrm{ESCLA} \% 2 \mathrm{E}+\mathrm{E}+407688 \% 2 \mathrm{ENUME} \% 2 \mathrm{E} \% 29+\mathrm{OU}-$ +\%28RE $\% 2 \mathrm{EACMS} \% 2 \mathrm{E}+\mathrm{ADJ} 2+407688 \% 2 \mathrm{EACMS} \% 2 \mathrm{E} \% 29 \&$ base=baseAcordaos\&url=http://tinyurl.com/c4f2nul $>$. Acesso em: 28 maio 2018.

BULOS, Uadi Lammêgo. Curso de direito constitucional. 5. ed. rev. e atualizada de acordo com a emenda constitucional n.64/2010. São Paulo: Saraiva, 2010.

CARLI, Ana Alice de. Bem de família do fiador e o direito humano fundamental à moradia. Rio de Janeiro: Lumen Juris, 2009.

CREDIE, Ricardo Arcoverde. Bem de Família: teoria e prática. 3. ed. São Paulo: Saraiva, 2010.

CRUZ E TUCCI, José Rogério (Coord.). A penhora e o bem de familia do fiador da locação. São Paulo: Revista dos Tribunais, 2003.

DEMÓCRITO, Reinaldo Filho. Bem de família do fiador de locação pode ser penhorado - a nova decisão do STF. Disponível em: <http://imp.org.br/v2008/?p=artigos\&id=16>. Acesso em: 25 maio 2014.

FORUM NACIONAL DE REFORMA URBANA. A função social da propriedade. Disponível em: $<$ http://www.forumreformaurbana.org.br/index.php/plataforma-fnru/a-funcao-social-da-propriedade.html >. Acesso em: 21 maio 2014.

GAGLIANO, Pablo Stolze; RODOLFO FILHO, Pamplona. Novo curso de direito civil: direito de família: as famílias em perspectiva constitucional. 2. ed. rev. atual. e ampl. São Paulo: Saraiva, 2012. 6 v.

GONÇALVES, Carlos Roberto. Direito civil brasileiro. 7. ed. rev. e atual. São Paulo: Saraiva, 2010. 6 v.

JUNQUEIRA, André Luiz; ROQUE, Caroline Meireles. Da possibilidade de penhora do bem de família do fiador: críticas ao projeto de lei $n^{\circ} 6.413$ de 2009 . Disponível em: $<$ http://www.oabsp.org.br/subs/santoanastacio/institucional/artigos/da-possibilidadede-penhora-do-bem-de-familia-do>. Acesso em: 25 maio 2014.

LENZA, Pedro. Direito constitucional esquematizado. 15. ed. rev. atual. e ampl. São Paulo: Saraiva, 2011.

MALUF, Carlos Alberto Dabus. Garantias locaticias de bens imóveis: da caução. In: CARVALHO NETO, Renato Torres de (Coord.). Revista do Advogado. São Paulo, 2010, n. 108, p.19-34, maio 2010.

MARCON, Danilo Zomer. $O$ direito fundamental à moradia na vigente Constituição da República Federativa do Brasil. Curso de Pós Graduação em Lato Sensu em Magistratura e Processo Civil da UNISUL - Campus Tubarão. 2006. 67 f.,Monografia (Pós-Graduação do Curso de Direto) - Universidade do Sul de Santa Catarina, Tubarão 2006, p. 58.

MARMITT, Arnaldo. Bem de família: legal e convencional. Rio de Janeiro: Aide, 1995.

NUNES, Hélio da Silva. A destinação da Lei n. 8.009/90: pessoas e coisas. Revista dos Tribunais, São Paulo, ano 90, v. 785, p. 148-149, mar. 2001. 
NUNES, Rizzatto. Curso de direito do consumidor. 4. ed. São Paulo: Saraiva, 2009.

SILVA, Edson Ferreira da. Direito à intimidade: de acordo com a doutrina, o direito comparado e a Constituição de 1988. São Paulo: Oliveira Mendes, 1998.

SILVA, José Afonso da. Curso de direito constitucional positivo. 30. ed. rev. e atual. até a Emenda Constitucional n. 56, de 20.12.2007. São Paulo: Malheiros, 2008.

TARTUCE, Flávio. Direito civil. 4. ed. rev. e atual. São Paulo: Método, 2009. 3 v.

VENOSA, Silvio de Salvo. Direito civil: direito de família. 11. ed. São Paulo: Atlas, $2011.6 \mathrm{v}$.

Recebido em: 29/05/2018

Aprovado em: 04/09/2018 